\title{
THERMAL-HYDRAULIC ANALYSIS OF IRT-4M IN REACTIVITY INSERTION ACCIDENT AT VR-1 REACTOR
}

\author{
FILIP FEJT
}

\begin{abstract}
Faculty of Nuclear Sciences and Physical Engineering, Czech Technical University in Prague, Czech Republic correspondence: filip.fejt@fjfi.cvut.cz
\end{abstract}

\begin{abstract}
The paper deals with thermal-hydraulic analysis during reactivity insertion accident, i.e. a step increase of nuclear system reactivity by $0.7 \beta_{\text {eff }}$, at VR-1 Reactor. The reactor utilizes IRT- $4 \mathrm{M}$ type of fuel assemblies, and even though these fuel assemblies are designed for an operation at the high-power research reactors, they might be also used for zero-power reactors. The thermal-hydraulic analyses must take into account several specific assumptions that are derived from VR-1 reactor specifications. The reactor does not require a forced water flow for a fuel cooling, the core is placed in an open vessel with atmospheric pressure, and amount of coolant water in the vessel is sufficient for providing the inlet water at room temperature for the whole event. Coolant circulation is expected to be formed only by natural convection.
\end{abstract}

KEYwords: IRT-4M, RIA, RELAP5, TRACE5, natural convection.

\section{INTRODUCTION}

Thermal-hydraulic analysis is a necessary part of every safety analyses report. The adequate cooling of the fuel assemblies must be ensured to maintain the core integrity during normal and abnormal operational transients, and accidents. In general, the research reactors may be designed for both natural convection and forced convection. The pool type research reactor VR-1 uses a natural convection of coolant to remove a core heat. The upward flow in natural convection is caused by different fluid densities of heated and unheated volumes.

Important point of safety analyses is an onset of nucleate boiling (ONB) 1 that is defined as a difference between the fuel surface temperature at the starting point of a nucleate boiling and the fuel surface temperature at a local cooling condition. Reaching a nucleate boiling significantly limits the heat transfer leading to a dramatic increase of the fuel surface temperatures in order to maintain the total heat flux. The main purpose of thermal-hydraulic analysis is to inspect all of possible events that may lead to an accident, and verify that normal and abnormal operation has safety margins before the critical level is reached.

\section{THERMAL-HYDRAULIC CODES}

Due to the various research reactor designs, i.e. operational mode, fuel type and applications, each reactor has a unique thermal-hydraulic characteristic. Computational codes must be capable of dealing with a broad range of different designs. Since the current codes are still based on dimensionless quantities that are used to calculate flow patterns in different fluid situation, the equations are mostly derived from simplified benchmarks and loops that must be considered similar to a problem of interest.
Although many well-known codes, e.g. RELAP, TRACE, PARET, have been designed for power reactors at first, they have been developed into general calculation tools that may be used even for research reactors. The main phenomena of VR-1 reactor analysis is natural convection, and therefore the chapter is followed by a brief description of natural convection part of the codes.

\subsection{RELAP5}

The RELAP5/MOD3.3 code has been developed for best-estimate transient simulation of light water reactor coolant systems during postulated accidents [2]. The code includes several behaviors effecting a reactor coolant, e.g. loss-of-coolant accident, anticipated transient without scram, loss of feedwater, loss of flow etc. Unlike its predecessors, RELAP5 series uses a two-fluid, nonequilibrium, nonhomogeneous, hydrodynamic model for transient simulation of the two-phase system behavior.

Convection calculations rely on evaluating forced convection, laminar convection, and natural convection and selecting the maximum of these values. The correlations are by Dittus-Boelter [3], Kays [4], and Churchill-Chu [5] respectively.

\subsection{TRACE}

TRACE has been designed to calculate best-estimate analyses of loss-of-coolant accidents, operational transients, accidents in pressurized light-water reactors and boiling light-water reactors [6]. The code includes multidimensional two-phase flow, nonequilibrium thermo-dynamics, generalized heat transfer, level tracking, and reactor kinetics.

The partial differential equations that describe twophase flow model are solved using finite volume numerical methods. Components are solved in one-dimension 
or three-dimensions when necessary. Timesteps are limited by Courant-limit factor to ensure the computational stability of an examined system. The Courantlimit depends on a phenomena and current conditions in a system. Description of this factor can be found in [2]. Similar to RELAP5, the TRACE follows a component-based approach to modeling a reactor system. Each part of the system is inserted as a unique component. List of components in the code is designed to cover all power plant models. After that all the components are connected as the user requires.

Expected mode of calculation in examined RIA is pre-critical heat flux region. The correlations are provided for the laminar and turbulent forced convection regimes and for natural convection. The wall heat transfer coefficient for single-phase liquid [6] convection is taken as the maximum of the values for laminar and turbulent forced convection and natural convection (1)

$$
h_{\mathrm{wl}}=\max \left\{h_{\mathrm{lam}}, h_{\mathrm{turb}}, h_{\mathrm{NC}}\right\},
$$

where $h_{\mathrm{NC}}$ is the wall heat transfer coefficient for natural convection, $h_{\text {lam }}$ is the wall heat transfer coefficient for laminar forced convection, and $h_{\mathrm{turb}}$ is the wall heat transfer coefficient for turbulent forced convection.

Heat transfer coefficient for natural convection uses correlations for both the laminar and turbulent regimes and a maximum of the two values is used to ensure continuity. The heat transfer coefficient is computed from 2

$$
h_{\mathrm{NC}}=\frac{k_{\mathrm{l}}}{D_{\mathrm{h}}} \cdot N u_{\mathrm{NC}},
$$

where $k$ is thermal conductivity evaluated at the bulk fluid temperature and $D_{\mathrm{h}}$ is the hydraulic diameter. The Nusselt numbers are given by (3) and (4)

$$
\begin{aligned}
& N u_{\text {NC,turb }}=0.1 \cdot\left(G r_{1} \cdot P r_{1}\right)^{1 / 3}, \\
& N u_{\text {NC,lam }}=0.59 \cdot\left(G r_{1} \cdot P r_{1}\right)^{1 / 4} .
\end{aligned}
$$

Both Grashof and Prandtl numbers are evaluated at bulk fluid temperature.

\section{VR-1 REACTOR MODEL}

The VR-1 core is placed in a vessel with large water reserve. During the transient the water reserve ensures the room temperature at the core inlet. Even though the transient may last several hundred seconds, the average water temperature in the vessel will not increase because the flow rate caused by natural convection is very small.

In order to maximize the first power peak, the coolant is expected to be stationary at the beginning of the simulation. This condition can be achieved when the main pump in the vessel is turned off and the reactor is operated at the very low power causing minimal flow velocity.
The IRT-4M fuel assemblies used the VR-1 reactor consist of 4,6 , or 8 fuel layers arranged in rounded rectangular tubes [7]. Each fuel layer is surrounded by cladding layer from both inner and outer side. Cladding layers are made of aluminium similar to fuel layers where the $\mathrm{UO}_{2}$ is dispersed also in aluminium. A thin layer thickness, both the fuel and the cladding, in addition to a high thermal conductivity of the aluminium leads to a very flat radial temperature profile in fuel assemblies.

The core is represented by an averaged 8-tube fuel assembly (Fig. 1) to comply with point kinetic equations that are integrated into the computational codes [8].

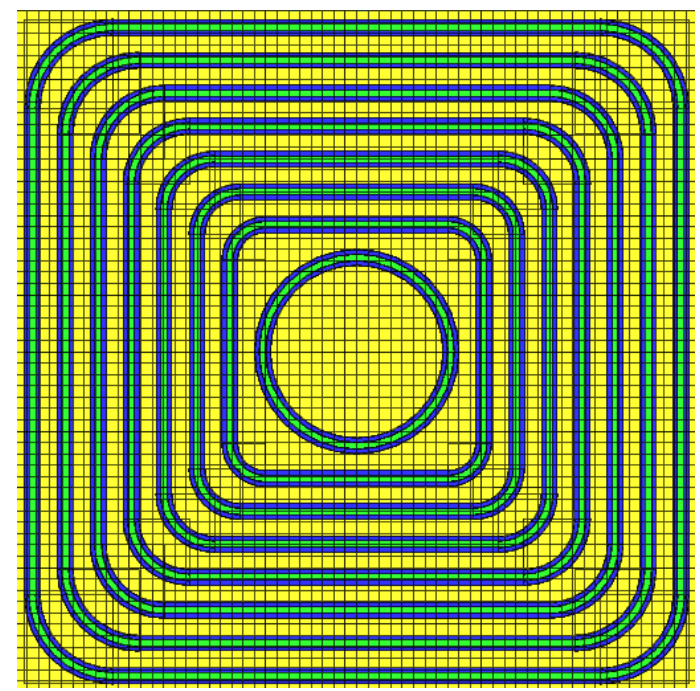

Figure 1. Top view of 8-tube IRT-4M fuel assembly (yellow - water coolant, blue - cladding layer, green fuel layer).

\subsection{RELAP5 SPECIFICATION}

Using the component-based structure of input files, a list of utilized components can be found in Tab. 1 The bottom plenum serves as a coolant distributing element at the bottom part of fuel assembly. Distributed coolant flows through the fuel assembly (each pipe represents one coolant flow area between heatstructures), and at the top of the fuel assembly the top plenum mixes the heated coolant that flows directly to the vessel water reserves. The model can be seen in Fig. 2,

\begin{tabular}{cc}
\hline Component & Number \\
\hline Pipe (FA coolant) & $8 \mathrm{x}$ \\
Pipe (Vessel) & $1 \mathrm{x}$ \\
Heatstructure (Fuel tubes) & $8 \mathrm{x}$ \\
Plenum & $2 \mathrm{x}$ \\
\hline
\end{tabular}

TABLE 1. List of RELAP5 components utilized in the single assembly VR-1 model. 


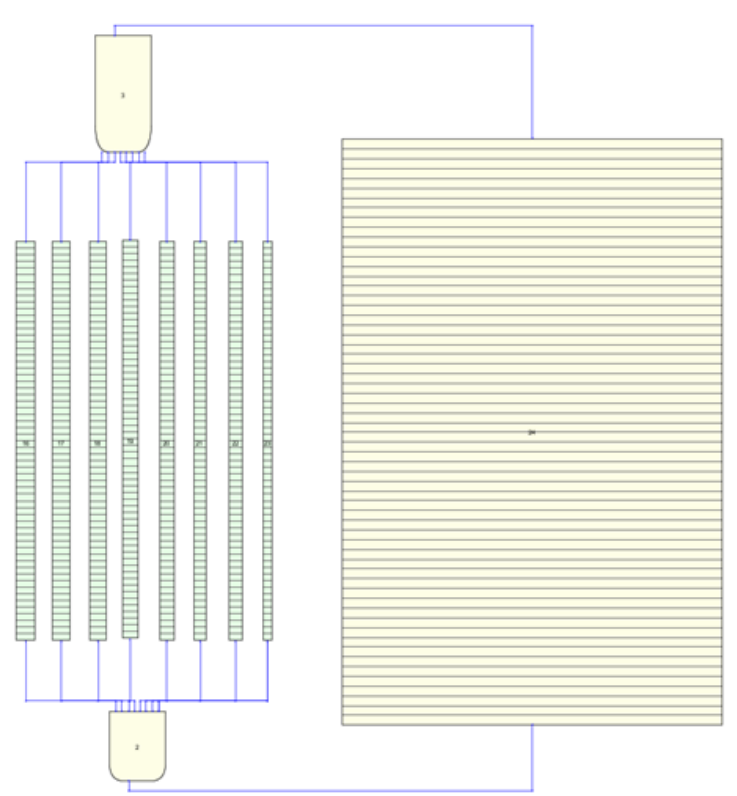

FigURE 2. RELAP5 model with green pipes connected to heatstructures, bottom and top plenum, and a large pipe serving as a reactor vessel.

\subsection{TRACE SPECIFICATION}

Unlike RELAP5 model, the TRACE model is not using the plenum component for distributing and mixing the coolant because it is assumed to be obsolete in current development. Its role has been taken by advanced pipe settings; unfortunately, the low dimensions of fuel assembly flow surfaces and complex flow distribution made it inapplicable in this model. Therefore the bottom and top plenum were replaced by independent pipes denying any interaction between coolant coming to/from flow surfaces. Similar idea had to be applied also to the pipe representing the vessel; the vessel is divided into 8 pipes. The model can be seen in Fig. 3. This pipe separation requires an extended usage of components (Tab. 2).

\begin{tabular}{cc}
\hline Component & Number \\
\hline Pipe (FA coolant) & $8 \mathrm{x}$ \\
Pipe (Vessel) & $8 \mathrm{x}$ \\
Heatstructure (Fuel tubes) & $8 \mathrm{x}$ \\
Pipe (Bottom plenum) & $4 \mathrm{x}$ \\
Pipe (Top plenum) & $4 \mathrm{x}$ \\
\hline
\end{tabular}

TABLE 2. List of TRACE components utilized in the single assembly VR-1 model.

\section{Results}

For the sake of clarity, the graphical interpretation of results follows two main rules - RELAP results are plotted with connected points and $-\mathrm{R}$ is added in the legend; TRACE results are plotted with separate points and $-\mathrm{T}$ is added in the legend. Each

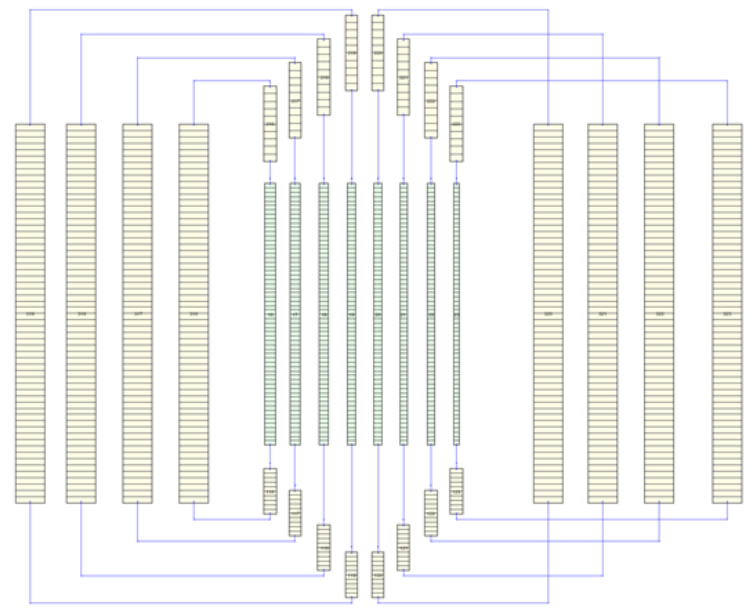

FigURE 3. TRACE model with green pipes connected to heatstructures, set of pipes serving as bottom and top plenum, and set of pipes serving as a reactor vessel.

spatial value is considered to be averaged over flow surface, therefore such a value has a two digit number representing a number of outer and inner fuel layer (fuel layer number starts from the outside of the fuel assembly: $1,2,3, \ldots, 8, \mathrm{v}$ denotes central area).

\subsection{REACTOR POWER OUTPUt}

The reactor power and the reactivity of the system can be seen in Fig. 4 The reactivity is increased to the value of $0.7 \beta_{\text {eff }}$ at $t=0.5 \mathrm{~s}$, after that the value is decreased by feedback effects created from both the fuel and the moderator. The reactivity increase starting at $t=20 \mathrm{~s}$ is caused by the slowly increasing coolant velocity effecting its heat removal capabilities. After 200 seconds the reactivity reaches the zero value.

\subsection{Coolant velocity}

Fig. 5 shows a fast velocity increase of coolant that causes the reactivity peak shown in Fig. 4. This analysis is valid as long as the initial coolant velocity is zero, i.e. vessel pump is turned off, and the reactor power is very low.

\subsection{Coolant temperatures}

The temperatures of flow surfaces are shown in Fig. 6 . No coolant reaches the boiling point during the occurring RIA event. It can be clearly seen that both RELAP5 and TRACE have a very good agreement in coolant temperatures between outside fuel layers. The difference between the codes is approx. $10^{\circ} \mathrm{C}$ in the middle of the fuel assembly.

\section{Conclusions}

Despite the equation differences that can be found in both codes, RELAP5 and TRACE code shows a very good agreement in both point kinetics and thermalhydraulic. Even though a difference can be observed 


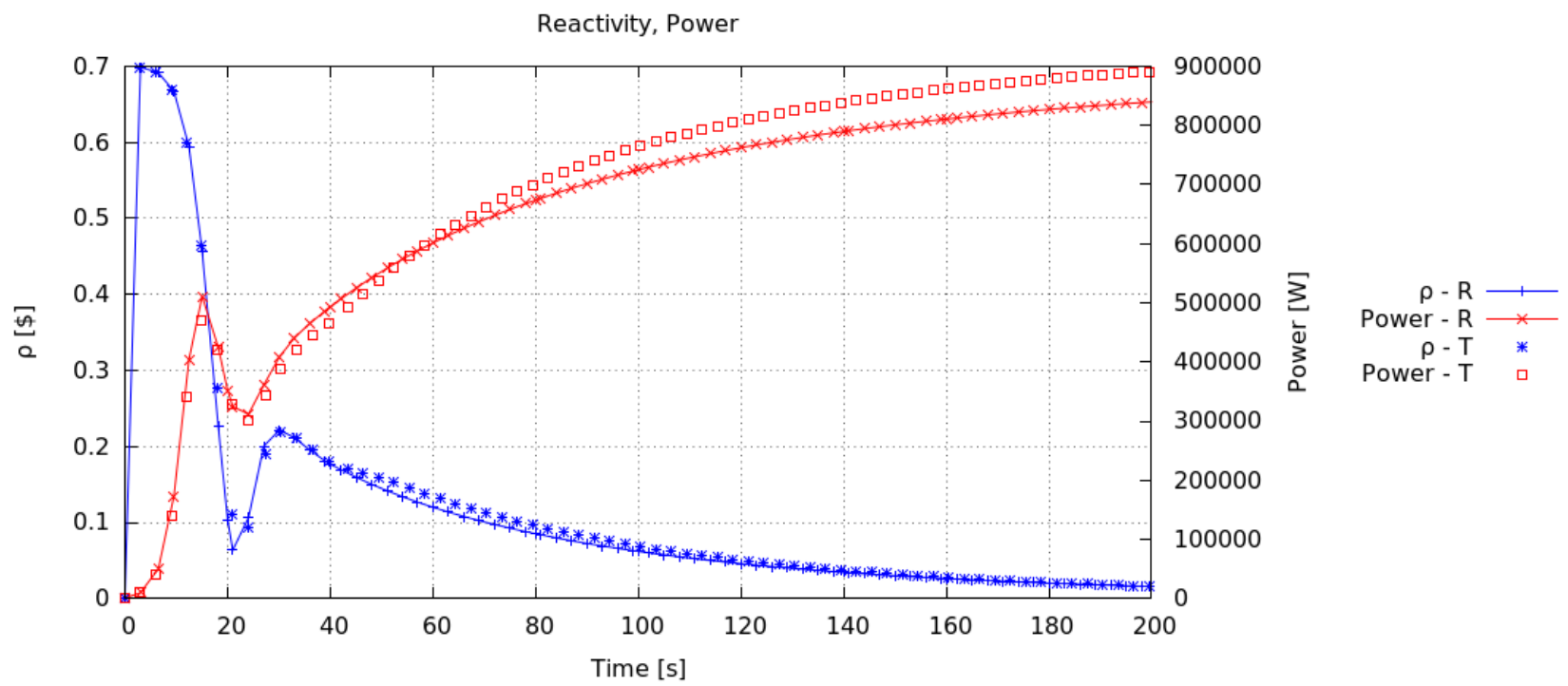

FiguRE 4. Reactor power and reactivity of system during step increase of reactivity accident by $0.7 \beta_{\text {eff }}$.

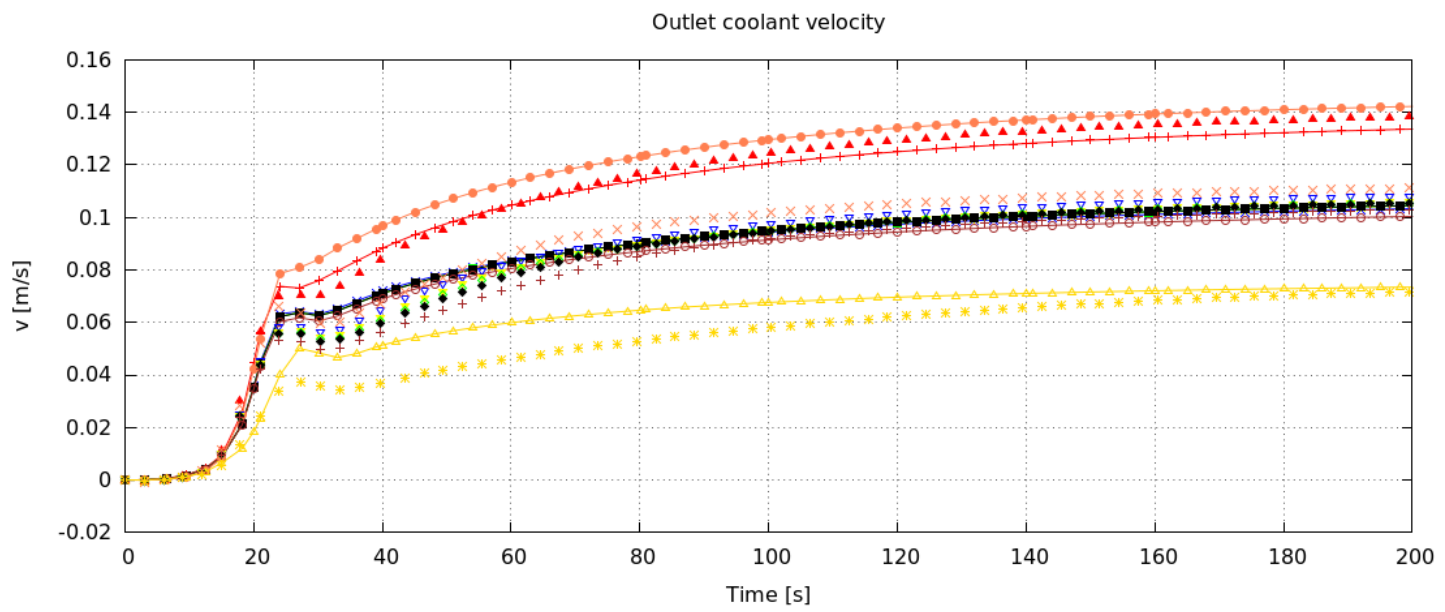

AAa-12 - R —

FAa-23 - R

FAa-34 - R

FAa-45 - R $\longrightarrow$

FAa-67 - R -

FAa-78 - R -

FAa-8v - R

FAa-12-T

FAa-23 - T

FAa-34 - T

FAa- $45-T$

FAa-56-T

FAa-67 - T

FAa-78 - T

FAa-8v - T

FigURE 5. Outlet coolant velocity during step increase of reactivity accident by $0.7 \beta_{\text {eff }}$.

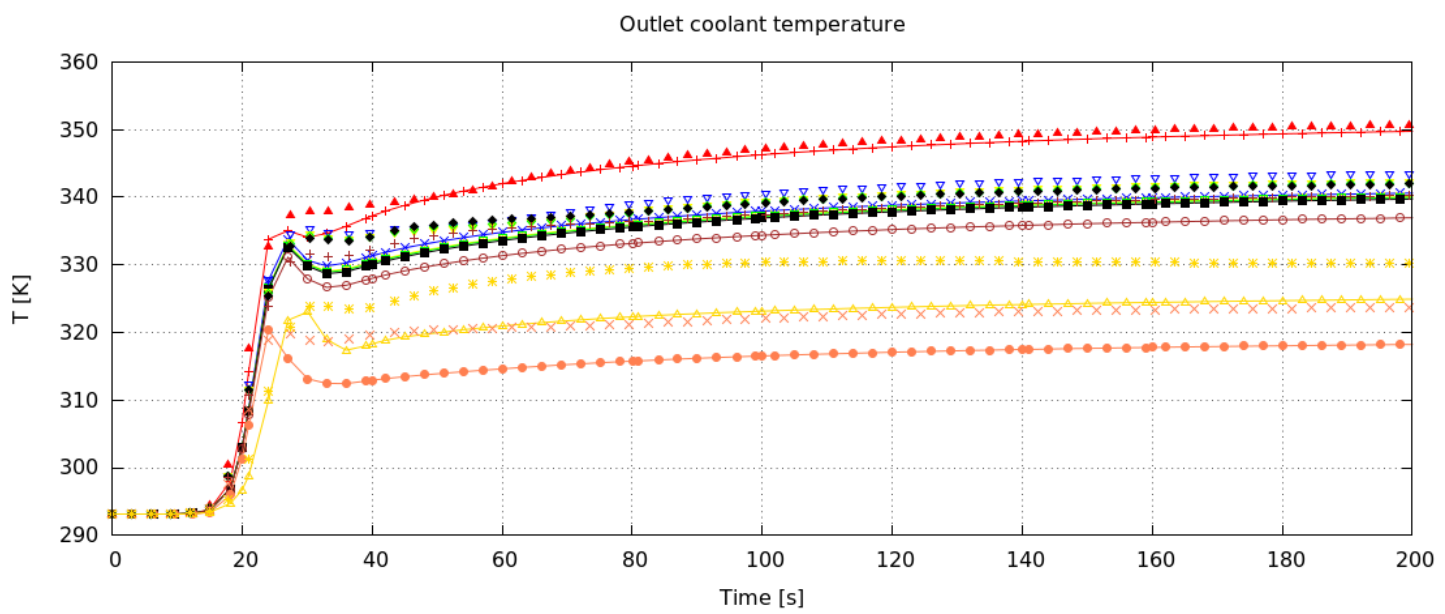

FAa-12 - R $\longrightarrow$

FAa-23-R $\rightarrow$

$\mathrm{FAa}-34-\mathrm{R}$

FAa-45 - R

FAa-56-R $\longrightarrow$

FAa-67-R $\longrightarrow$

FAa-78 - R

FAa-8v - R

FAa-12 - T

FAa-23 - T

FAa-34 - T

FAa-45 - T

FAa-56 - T

FAa-56 - T

FAa-67- - T

FAa-8v - T

FiguRE 6. Outlet coolant temperature during step increase of reactivity accident by $0.7 \beta_{\text {eff }}$. 
in the final power, it has no effect on maximal outlet coolant temperature. Higher power, i.e. higher heating, is always compensated by an increase of velocity of a coolant that leads to a temperature decrease. The coolant velocity can be compared to negative reactivity feedback effects.

The separate pipes can be considered as the most significant difference between both models. This effect can be seen in inner flow cross sections where the temperature difference can reach up to $10^{\circ} \mathrm{C}$. Since the maximal temperatures are reached in outer flow cross sections and both codes compute the same coolant temperature, it can be safely assumed that the separate pipe model does not effect the maximal temperatures.

\section{REFERENCES}

[1] J. Daeseong, P. Suki, P. Jonghark, et al. Cooling capacity of plate type reserach reactors during the natural convective cooling mode. Progress in Nuclear Energy 56:37-42, 2012.

[2] U.S. Nuclear Regulatory Commission. RELAP5/MOD3.3 CODE MANUAL VOLUME I: Code Structure, System Models, and Solution Methods, 2010.
Division of Systems Research, Office of Nuclear Regulatory Research.

[3] F. Dittus, L. Boelter. Heat transfer in automobile radiators of the tubular type. Publications in Engineering 2:443-461, 1930.

[4] W. Kays. Numerical solution for laminar flow heat transfer in circular tubes. American Society of Mechanical Engineers 77:1265-1274, 1955.

[5] S. Churcill, H. Chu. Correlating equations for laminar and turbulent free convection from a vertical plate. International Journal of Heat and Mass Transfer 18:1323-1329, 1975.

[6] U.S. Nuclear Regulatory Commission. TRACE V5.840 THEORY MANUALS: Field Equations, Solution Methods, and Physical Models, 2013. Division of Systems Research, Office of Nuclear Regulatory Research.

[7] J. Rataj, L. Sklenka. Calculations and measurement at the training reactor vr-2. International Atomic Energy Agency, Publications 2007.

[8] J. Daeseong, P. Jonghark, C. Heetaek. Development of thermal hydraulic and margin anlysis code for steady state forced and natural convective cooling of plate type fuel research reactor. Progress in Nuclear Energy 71:39-51, 2014. 